\title{
Peningkatan Kemampuan Komunikasi Matematis Siswa Menggunakan Model Pembelajaran Hybrid Learning
}

\author{
Widya Dwi Indriani ${ }^{1}$, Laili Habibah Pasaribu ${ }^{2}$ \\ 1, 2 Program Studi Pendidikan Matematika, Fakultas Keguruan dan Ilmu Pendidikan, Universitas Labuhanbatu, \\ Jl. Sisingamangaraja No 125 - A KM 3,5, Rantauprapat, Sumatera Utara Indonesia \\ imdri232018@gmail.com
}

\begin{abstract}
The ability to communicate is a very important potential to be fulfilled by students, the same is the case with learning mathematics. Hybrid Learning is a learning model that combines learning communication with face-toface and online (discussion/chat forums). The implementation of Hybrid Learning able to foster mutualism and the quality of learning. The purpose of this study was to determine whether there was an increase in students' mathematical communication skills with the Hybrid Learning learning model. The analysis of this research data is a non-parametric test, namely the Wilcoxon test which uses a prerequisite test with a normality test, a homogeneity test, and a hypothesis test. Wilcoxon test results are worth 0.000 which means it is less than 0.05 . So, it can be concluded that "the hypothesis is accepted" means that there is an increase in students' mathematical communication skills with the Hybrid Learning learning model. Based on the test results above, it can be concluded that there is an increase in students' mathematical communication skills in learning mathematics that is taught using conventional learning models and hybrid learning learning and there are differences in students' mathematical communication skills in learning mathematics with conventional learning models and hybrid learning learning models.
\end{abstract}

Keywords: Mathematical communication, Hybrid Learning.

\begin{abstract}
Abstrak
Kemampuan komunikasi merupakan potensi yang sangat penting untuk disanggupi oleh siswa, sama hal nya dengan pembelajaran matematika. Hybrid Learning adalah model pembelajaran yang menggabungkan komunikasi pembelajaran dengan tatap muka (face to face) dan online (forum diskusi/ chatting). Implementasi pembelajaran Hybrid Learning mampu manumbuhkan mutualisme serta mutu pembelajaran. Tujuan penelitian ini adalah untuk mengetahui apakah terdapat peningkatan kemampuan komunikasi matematis siswa dengan model pembelajaran Hybrid Learning. Analsis data peneltian ini uji non parametrik yaitu uji wilcoxon yang menggunakan uji prasyarat dengan uji normalitas, uji homogenitas dan uji hipotesis. Hasil Pengujian wilcoxon yang bernilai 0,000 yang berarti lebih kecil dari 0,05. Maka dapat disimpulkan bahwa "hipotesis diterima" artinya terdapat peningkatan kemampuan komunikasi matematis siswa dengan model pembelajaran Hybrid Learning. Berdasarkan hasil uji diatas dapat disimpulkan bahwa terdapat peningkatan kemampuan komunikasi matematis siswa dalam pembelajaran matematika yang di ajarkan menggunakan model pembelajaran konvensional dan pembelajaran hybrid learning dan terdapat perbedaan kemampuan komunikasi matematis siswa dalam pembelajaran matematika dengan model pembalajaran konvensional dan model pembelajaran hybrid learning.
\end{abstract}

Kata kunci: Komunikasi Matematis, Hybrid Learning

Copyright (c) 2021 Widya Dwi Indriani, Laili Habibah Pasaribu

$\triangle$ Corresponding author: Widya Dwi Indriani

Email Address: imdri232018@gmail.com (Jl. Sisingamangaraja No 125 - A KM 3,5, Rantauprapat)

Received 23 June 2021, Accepted 07 August 2021, Published 13 Januari 2022

\section{PENDAHULUAN}

Matematika merupakan ilmu yang diperlukan manusia karena menjadi alas dari perkembangan teknologi saat ini dan berprofesi penting dalam beraneka disiplin ilmu serta membangun pemikiran manusia (Pasaribu,2021) Matematika menjadi mata pelajaran yang harus di ajarkan.Semua level pendidikandimulai di sekolah dasar untuk membekali siswa dengan pemikiran logis, sistematis, analitis, kritis dan kreatif serta potensi untuk bekerja dalam kelompok. Kompetensi tersebut diperlukan bagi siswa agar dapat mengendalikan dan menggunakan pengetahuan untuk 
penyesuaian dan berdaya saing. Menurut (Pasaribu, 2016) matematika merupakan ilmu dasar, yang memiliki hubungan kuat dengan segala jenis ilmu pengetahuan. Menurut (Aritonang \& Safitri, 2021) matematika adalah ilmu pengetahuan yang pasti yang mengedepankan pemahaman siswa dari pada hafalan.

Badan Standart Nasional Pendidikan (BSNP) standart kompetensi dan kompetensi dasar tahun 2006 menurut (Riadi \& Retnawati, 2014) diadakannya pembelajaran matematika bertujuan untuk :

1. Memahami konsep matematika, menjelaskan antar konsep dan menerapkan konsep atau algoritma secara fleksibel, ringkas efesien,dan ringkas dalam menyelesaikan soal

2. Menerapkan intelek tentang pola dan sifat. Menggunakan manipulasi matematika dalam membuat generalisasi matematika, merakit bukti atau menjabarkan gagasan dan pernyataan matematika.

3. Menyelesaikan masalah yang mencakup kemampuan menginterprestasikan masalah, menskema model matematika, menyelesaikan model dan mempresentasikan solusi yang diperoleh.

4. Mengomunikasikan pendapat dengan simbol, table, diagram, atau media lain untuk memperjelas keadaan atau masalah.

5. Mempunyai sikap menghargai manfaat matematika dalam kehidupan yaitu mempunyai rasa ingin tahu, perhatian dan minat dalam mempelajari matematika, serta sikap ulet dan percaya diri dalam pemecahan masalah.

Kemampuan komunikasi menurut (Habibah, 2016) merupakan potensi yang sangat penting untuk disanggupi oleh siswa, sama hal nya dengan pembelajaran matematika. Pembelajaran matematika memerlukan potensi - potensi khusus untuk dapat mengasosiasikan, menghamparkan hingga menyelesaikan setiap permasalahan matematika. Sedangkan menurut (Nurhanifah et al., 2021) Kemampuan komunikasi matematis adalah potensi yang dimiliki siswa dalam menyuplai ide matematika secara verbal maupun bentuk tertulis. Kemampuan ini dapat ditingkatkan melalui proses pembelajaran disekolah, diantaranya dalam proses pembelajaran matematika dikarenakan ilmu matematika merupakan ilmu nalar yang dapat menguraikan potensi berfikir siswa. Menurut (Rianti Rahmalia et al., 2020) fungsi penting potensi komunikasi matematis dalam pembelajaran matematika ini untuk membangun berbagai rancangan matematika atau menumbuhkan pengetahuan siswa.

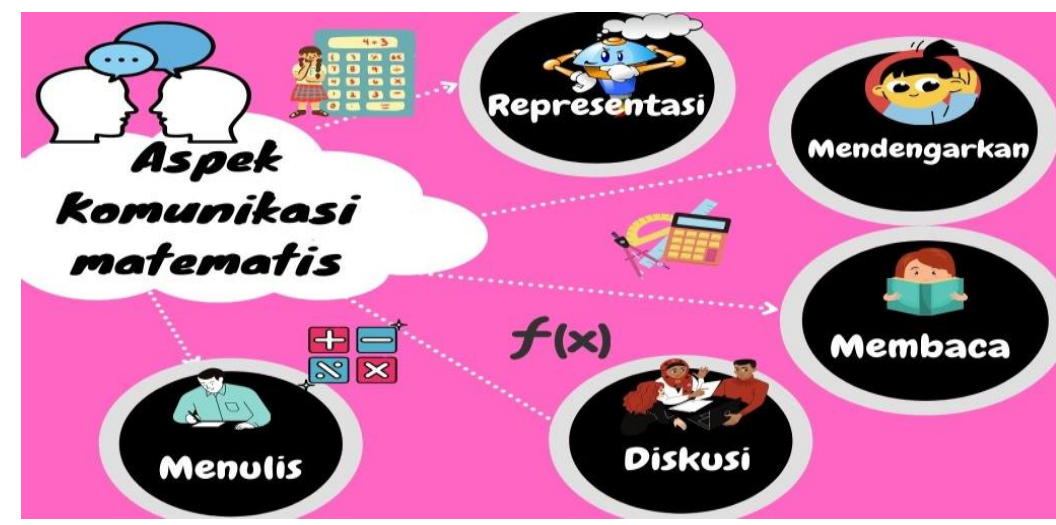

Gambar 1. Aspek Komunikasi Matematis 
Peningkatan Kemampuan Komunikasi Matematis Siswa Menggunakan Model Pembelajaran Hybrid Learning, Widya Dwi Indriani, Laili Habibah Pasaribu

Berdasarkan gambar 1 diatas Aspek komunikasi matematis menurut (Mahadewi et al., 2020) adalah:

1. Representasi yaitu mengolah bentuk sebagai hasil translasi dari suatu masalah atau ide, translasi suatu diagram untuk model fisik ke dalam symbol atau kata - kata.

2. Mendengarkan adalah mendengarkan secara hati - hati terhadap pertanyaan teman dalam suatu grup dapat membantu siswa mengkonstuksi lebih lengkap pengetahuan matematika dan mengatur strategi jawaban yang levih efektif.

3. Membaca adalah aktivitas membaca teks secara aktif untuk mencari jawaban atas pertanyaan yang telah disusun.

4. Diskusi merupakan sarana untuk mengungkapkan dan mereleksikan pikiran siswa.

5. Menulis adalah suatu kegiatan yang dilakukan secara sadar untuk mengungkapkan dan merefleksikan pikiran.

Relevannya menurut (Purnamasari \& Afriansyah, 2021) kemampuan komunikasi matematis mewajibkan guru harus mengerti bagaimana komunikasi matematis dan pendapat akan perspektif atau parameter dari kemampuan komunikasi sehingga pengoprasian pembelajaran matematika perlu dipertimbangkan sebaik mungkin agar tujuan peningkatan kemampuan komunikasi matematis dapat tercapai.

Salah satu model pembelajaran yang cocok digunakan untuk meningkatkan kemampuan komunikasi matematis siswa yaitu model pembelajaran Hybrid Learning. Menurut (Galus \& Tahun, 2021) Hybrid Learning adalah pendidikan yang memadukan pembelajaran tatap muka dengan pembelajaran $e$ - learning. Kemajuan informasi dan komunikasi telah menstimulasi munculnya beragam inovasi pembelajaran dalam dunia pendidikan termasuk $e$ - learning. Menurut (Putra, 2015) Pembelajaran Hybrid Learning mengarah untuk membagikan pengalaman sepositif dan sepraktis mungkin dengan cara memadukan pertemuan tatap muka di kelas dengan peningkatan ranah $e-$ learning. Metode ini pun merupakan preferensi untuk menumbuhkan daya guna, daya tarik dan efesiensi yang lebih besar sehingga berupaya berhubungan antar manusia dengan lingkungan belajar yang bermacam - macam. Pembelajaran Hybrid Learning juga memberikan peluang agar menjadi lebih baik secara terisolasi dan berdampingan.

Hybrid learning adalah pembelajaran yang bisa dilakukan secara tatap muka ataupun virtual dengan bantuan dari internet. Menurut (Nur et al., 2017) Hybrid Learning adalah model pembelajaran yang menggabungkan komunikasi pembelajaran dengan tatap muka (face to face) dan online ( forum diskusi/ chatting). Implementasi pembelajaran Hybrid Learning mampu manumbuhkan mutualisme serta mutu pembelajaran. 


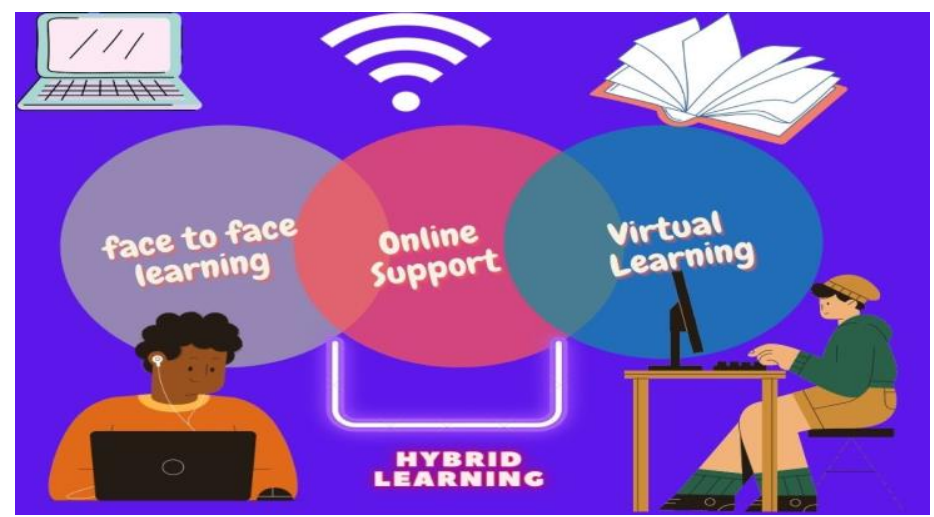

Gambar 2. hybrid learning

Hybrid Learning berhasil berprofesi sebagai pembelajaran yang trend. Menurut (Ramdhani T., 2020) jenis pembelajaran ini mampu dijadikan penyelesaian dalam usaha menumbuhkan kualifikasi komunikasi matematis siswa. Siswa dibiasakan saling berhubungan, berpolemik, bertukar pendapat atau ide tentang persoalan tertentu sehingga siswa berpengalaman membangun kemampuan komunikasi matematisnya secara lisan maupun tulisan. Dengan memuncaknya mutu dan korelasi pembelajaran, siswa dapat dengan mudah berhubungan baik dengan guru atau dengan siswa yang lain sehingga dapat membentuk siswa yang percaya diri dalam proses pembelajaran, maka dari itu peneliti mengaplikasikan Hybrid Learning sebagai model pembelajaran untuk meningkatkan komunikasi matematis siswa. Menurut (Febnesia et al., 2021)Model pembelajaran ini akan mempermudah siswa dalam mengakses materi pembelajaran, siswa pun dapat belajar kapan saja dan dimana saja. Selain itu pengkajian Hybrid Learning ditaksir dapat meningkatkan kemampuan komunikasi matematis siswa dalam pembelajaran matematika.

Hasil dari penelitian Munawaroh,2018 (Hikmawati et al., 2019) menyatakan bahwa kemampuan komunikasi matematis siswa pada saat ini masih sangat rendah.Fakta dilapangan juga menunjukkan bahwa ide matematis siswa belum tersampaikan dengan baik ketika dihadapkan pada suatu permasalahan matematika, termasuk pada soal yang didalamnya memiliki simbol ataupun gambar, yang membuat siswa kesulitan untuk memahami permasalahan dalam soal tersebut. Menurut latar belakang yang sudah digambarkan, maka peneliti tertarik membuat penelitian dengan judul: "Peningkatan Kemampuan Komunikasi Matematis Siswa Manggunakan Model Pembelajaran Hybrid Learning”,

\section{METODE}

Penelitian ini dilakukan di SMP N 4 satu atap Desa Pekan Tolan Kecamatan Kampung Rakyat Kabupaten Labuhanbatu Selatan, metode penelitian yang peneliti gunakan adalah metode penelitian kuantitatif. Menurut (Rukajat,A; 2018) penelitian kuantitatif adalah adalah penelitian yang pengambilan datanya berdasarkan data konkrit, data penelitian di hitung berdasarkan statistik sebagai alat untuk uji penghitungan, yang bersangkutan dengan masalah sehingga menghasilkan sebuah 
Peningkatan Kemampuan Komunikasi Matematis Siswa Menggunakan Model Pembelajaran Hybrid Learning, Widya Dwi Indriani, Laili Habibah Pasaribu

kesimpulan. Dalam penelitian ini menggunakan penelitian Quasy Ekperimen Design sehingga terpilih kelas VIII A dengan menggunakan model pembelajaran Hybrid learning. Teknik pengambilan sampel menggunakan teknik sampel random sampling, menurut Sugiyono (dalam Afiani, 2017) teknik sampel random sampling adalah teknik pengambilan sampel dari anggota populasi yang dilakukan secara acak tanpa memperhatikan strata yang ada dalam populasi itu Siswa kemudian diberi soal tes kemampuan komunikasi matematis menggunakan indikator dari komponen aspek kemampuan komunikasi matematis menurut (Wahyuni et al., 2020)adalah yaitu: (1) Representasi, (2) Mendengarkan (3) Membaca (4) Diskusi (5) Menulis.

Dalam penelitian ini terdapat dua variabel yaitu variable $\mathrm{X}$ sebagai variable terikat yakni komunikasi matematis dan variable Y sebagai variable bebas yaitu Pembelajaran Hybrid Learning. Populasi dalam penelitian ini adalah siswa SMP N 4 Satu Atap Kecamatan Kampung Rakyat Kabupaten Labuhanbatu Selatan, dan sampel penelitian ini yaitu siswa kelas VIII SMP N 4 satu atap Kampung Rakyat sebanyak 30 siswa. Teknik pengumpulan data menggunakan Pretest dan Posttest. Instrumen penelitian ini terdiri dari tes berupa soal tes yaitu pretest dan posttest untuk melihat apakah ada peningkatan kemampuan komunikasi matematis siswa. Analsis data peneltian ini uji ANOVA yang menggunakan uji prasyarat dengan uji normalitas, uji homogenitas dan uji hipotesis.

\section{HASIL DAN DISKUSI}

Penelitian ini dlakukan untuk membuktikan apakah ada peningkatan antara Kemampuan Komunikasi Matematis Siswa (X) dengan Model Pembelajaran Hybrid Learning (Y) yang menggunakan teknik analisis data uji non parametrik yaitu uji wilcoxon. Sebelum menyimpulkan hipotesis, terlebih dahulu data tes essay siswa dianalisis deskriptif, kemudian diuji normalitas dan homogenitas serta uji wilcoxon.

\section{Analisis Deskriptif}

Analisis deskriptif dilakukan untuk memberikan gambaran/ deskripsi suatu data, agar data yang tersaji mudah dipahami bagi yang membacanya. Adapun hasil analisis deskriptif dapat dilihat pada tabel berikut :

Tabel 1. Analisis Deskriptif

\begin{tabular}{|c|c|c|c|c|c|c|c|c|c|}
\hline & \multirow[b]{2}{*}{$\mathbf{N}$} & \multirow[b]{2}{*}{ Mean } & \multirow[b]{2}{*}{ SD } & \multirow[b]{2}{*}{$\begin{array}{l}\text { Std. } \\
\text { Error }\end{array}$} & \multicolumn{2}{|c|}{$\begin{array}{l}95 \% \text { Confidence } \\
\text { Interval for Mean }\end{array}$} & \multirow[b]{2}{*}{ Minimum } & \multirow[b]{2}{*}{ Maximum } \\
\hline & & & & & & $\begin{array}{l}\text { Lower } \\
\text { Bound }\end{array}$ & $\begin{array}{l}\text { Upper } \\
\text { Bound }\end{array}$ & & \\
\hline \multirow[t]{3}{*}{ Pretest } & $\begin{array}{l}\text { Kelas } \\
\text { Konvension } \\
\text { al }\end{array}$ & 15 & 53.20 & 10.483 & 2.707 & 47.39 & 59.01 & 40 & 70 \\
\hline & \begin{tabular}{|l} 
Kelas \\
Hybrid \\
Learning
\end{tabular} & 15 & 59.27 & 10.354 & 2.673 & 53.53 & 65.00 & 36 & 80 \\
\hline & Total & 30 & 56.23 & 10.692 & 1.952 & 52.24 & 60.23 & 36 & 80 \\
\hline
\end{tabular}




\begin{tabular}{|l|l|r|r|r|r|r|r|r|r|}
\hline Postest & $\begin{array}{l}\text { Kelas } \\
\text { Konvension } \\
\text { al }\end{array}$ & 15 & 69.80 & 7.262 & 1.875 & 65.78 & 73.82 & 53 & 83 \\
\cline { 2 - 8 } & $\begin{array}{l}\text { Kelas } \\
\text { Hybrid } \\
\text { Learning }\end{array}$ & 15 & 72.00 & 6.568 & 1.696 & 68.36 & 75.64 & 60 & 83 \\
\hline & Total & 30 & 70.90 & 6.895 & 1.259 & 68.33 & 73.47 & 53 & 83 \\
\hline
\end{tabular}

Dari tabel di atas berdasarkan nilai Mean pada Posttest Kelas konvensional yaitu sebesar 69,80 sedangkan nilai mean pada kelas hybrid learning yaitu sebesar 72,00 maka dari tabel diatas membuktikan bahwa terdapat peningkatan kemampuan komunikasi matematis siswa yang menggunakan model pembelajaran pembelajaran Konvensional dan model pembelajaran hybrid learning.

\section{Uji Normalitas}

Uji normalitas dilakukan untuk mengetahui apakah data yang diperoleh berdistribusi normal atau tidak. Data yang diuji adalah data hasil pretest dan posttes siswa. Bentuk hipotesis untuk uji normalitas adalah sebagai berikut:

$\mathrm{H}_{0}$ : Data berdistribusi normal

$\mathrm{H}_{1}$ : Data tidak berdistribusi normal

Adapun criteria dalam pengujian adalah jika nilai signifikan (Sig.) > 0,05 maka data normal dan jika signifikan (Sig.) $<0,05$ maka data tidak normal

Berikut adalah hasil Uji Normalitas:

Tabel 2. Uji Normalitas

\begin{tabular}{|l|l|r|r|r|r|r|r|}
\hline \multirow{2}{*}{} & & \multicolumn{3}{|c|}{ Kolmogorov-Smirnov $^{\mathrm{a}}$} & \multicolumn{3}{|c|}{ Shapiro-Wilk } \\
\cline { 2 - 8 } & Kelas & Statistic & \multicolumn{1}{c|}{$\mathrm{df}$} & \multicolumn{1}{c|}{ Sig. } & Statistic & \multicolumn{1}{c|}{ df } & \multicolumn{1}{c|}{ Sig. } \\
\hline Pretest & Kelas Konvensional & .221 & 15 & 0.048 & .875 & 15 & 0.040 \\
\cline { 2 - 8 } & $\begin{array}{l}\text { Kelas Hybrid } \\
\text { Learning }\end{array}$ & .159 & 15 & $0.200^{*}$ & .962 & 15 & $\mathbf{0 . 7 3 2}$ \\
\hline Postest & Kelas Konvensional & .137 & 15 & $0.200^{*}$ & .956 & 15 & $\mathbf{0 . 6 1 5}$ \\
\cline { 2 - 8 } & $\begin{array}{l}\text { Kelas Hybrid } \\
\text { Learning }\end{array}$ & .247 & 15 & 0.014 & .898 & 15 & 0.088 \\
\hline
\end{tabular}

*. This is a lower bound of the true significance.

Dalam tabel diatas mengacu pada kolom Shapiro-Wik yaitu nilai signifikan pada pretest dikelas konvensional sebesar $0,040<0,05$ sehingga data pretest pada kelas konvensional tidak berdistribusi normal dan di kelas Hybrid Learning yaitu sebesar 0,732 yang > 0,05 data pretest pada kelas hybrid learning berdistribusi normal. Sedangkan nilai signifikan pada posttest dikelas konvensional yaitu 0,615 yang berarti data posttest pada kelas konvensional berdistribusi normal dan pada kelas hybrid learning yaitu 0,088 yang berarti bahwa data posttest pada kelas hybrid learning 
Peningkatan Kemampuan Komunikasi Matematis Siswa Menggunakan Model Pembelajaran Hybrid Learning, Widya Dwi Indriani, Laili Habibah Pasaribu

tidak berdistribusi normal. Pada data pretest di kelas konvensional dan data posttest di kelas hybrid learning tidak berdistribusi normal maka diuji dengan uji wilcoxon.

\section{Uji Homogenitas}

Uji homogenitas digunakan untuk memperlihatkan bahwa dua atau lebih kelompok sampel berasal dari populasi yang memiliki varians yang sama. Uji Homogenitas dilakukan dengan uji Homogenity of Variance Test pada One-Way Anova dengan taraf signifikan 0,05. Berdasarkan tujuan dalam penelitian ini untuk melihat apakah ada perbedaan komunikasi matematis siswa berdasarkan model pembelajaran konvensional dengan model pembelajaran hybrid learning.

$\mathrm{H}_{0}$ : Tidak terdapat perbedaan varians nilai model pembelajaran antara nilai model pembelajaran

Konvensional dengan model pembelajaran Hybrid Learning

$\mathrm{H}_{1}$ : Terdapat perbedaan varians nilai model pembelajaran antara nilai model pembelajaran konvensional dan model pembelajaran Hybrid Learning.

Adapun kriteria dalam pengujian adalah jika signifikan (Sig.) > maka $\mathrm{H}_{0}$ diterima dan jika signifikan (Sig.) $<0,05$ maka $\mathrm{H}_{0}$ ditolak.

Tabel 3. Uji Homogenitas

\begin{tabular}{|l|r|r|r|r|}
\hline \multicolumn{7}{|c|}{ Test of Homogeneity of Variances } \\
\hline & $\begin{array}{c}\text { Levene } \\
\text { Statistic }\end{array}$ & df1 & \multicolumn{1}{c|}{ df2 } & \multicolumn{1}{c|}{ Sig. } \\
\hline Pretest & .251 & 1 & 28 & 0.620 \\
\hline Postest & .237 & 1 & 28 & 0.630 \\
\hline
\end{tabular}

Hasil uji homogen diatas menunjukkan $\mathrm{p}$ (value) sig pada pretes sebesar 0,620 dan pada posttest yaitu sebesar 0,630 lebih besar dari 0,05 sehingga $\mathrm{H}_{0}$ diterima.

\section{Uji Wilcoxon}

Tabel 4. Uji Wilcoxon

\begin{tabular}{|l|r|}
\hline \multicolumn{2}{|c|}{ Test Statistics $^{\mathrm{b}}$} \\
\hline $\mathrm{Z}$ & \multicolumn{1}{|c|}{ posttest - pretest $^{-4.593^{\mathrm{a}}}$} \\
\hline Asymp. Sig. (2-tailed) & 0.000 \\
\hline $\begin{array}{l}\text { a. Based on negative ranks. } \\
\text { b. Wilcoxon Signed Ranks Test }\end{array}$ \\
\hline
\end{tabular}

Berdasarkan tabel 4 diketahui Asymp.Sig. (2-tailed) bernilai 0,000 yang berarti lebih kecil dari 0,05 . Maka dapat disimpulkan bahwa "hipotesis diterima" artinya terdapat peningkatan kemampuan komunikasi matematis siswa dengan model pembelajaran Hybrid Learning. Berdasarkan hasil uji diatas dapat disimpulkan bahwa terdapat peningkatan kemampuan komunikasi matematis siswa dalam pembelajaran matematika yang di ajarkan menggunakan model pembelajaran konvensional dan pembelajaran hybrid learning dan terdapat perbedaan kemampuan komunikasi 
matematis siswa dalam pembelajaran matematika dengan model pembalajaran konvensional dan model pembelajaran hybrid learning.

\section{KESIMPULAN}

Berdasarkan hasil penelitian dan diskusi mengenai Peningkatan Kemampuan Komunikasi Matematis Siswa Menggunakan Model Pembelajaran Hybrid Learning di SMP Negeri 4 Satu Atap Kampung Rakyat maka dapat disimpulkan bahwa terdapat peningkatan kemampuan komunikasi matematis siswa yang menggunakan model pembelajaran hybrid learning.

\section{UCAPAN TERIMA KASIH}

Terima kasih penulis ucapkan kepada Bapak/Ibu Kepala Sekolah SMP Negeri 04 Satu Atap Kampung Rakyat yang sudah memberikan izin dan membantu penulis dalam menyelesaikan penelitian ini. Terima kasih kepada Bapak/Ibu dosen yang sudah memberikan arahan selama ini sehingga dapat menyelesaikan publikasi ini.

\section{REFERENSI}

Afiani, N. (2017). Pengaruh Kemampuan Komunikasi Matematis dan Kemandirian Belajar terhadap Prestasi Belajar Matematika. JKPM (Jurnal Kajian Pendidikan Matematika), 2(1), 1. https://doi.org/10.30998/jkpm.v2i1.1844

Aritonang, I., \& Safitri, I. (2021). Pengaruh Blended Learning Terhadap Peningkatan Literasi Matematika Siswa. Jurnal Cendekia: Jurnal Pendidikan Matematika, 5(1), 735-743. https://doi.org/10.31004/cendekia.v5i1.555

Galus, S. S., \& Tahun, N. (2021). Kesiapan Sekolah Dalam Pengelolaan Model Pembelajaran Hybrid Learning Di SMA Kota Gorontalo pembelajaran . Hal tersebut dikarenakan ketika menerapkan model pembelajaran yang teknologi informasi seperti sekarang ini . Saat ini proses pembelajaran di Indone. Student Journal of Educational Management, 1(2), 41-55.

Habibah, L. (2016). Peningkatan Kemampuan Komunikasi Siswa Melalui Pendekatan Problem Based Learning (PBL) terhadap Siswa MTs N KELAS VII. Jurnal Pembelajaran Dan Matematika Sigma (JPMS), 2(1). http://jurnal.ulb.ac.id/index.php/sigma/article/viewFile/1294/1277

Hikmawati, N. N., Nurcahyono, N. A., \& Balkist, P. S. (2019). Kemampuan Komunikasi Matematis Siswa Dalam Menyelesaikan Soal Geometri Kubus Dan Balok. Prisma, 8(1), 68. https://doi.org/10.35194/jp.v8i1.648

Journal, D., Education, O., Febnesia, H., Nurtanto, M., \& Abdillah, H. (2021). Pengaruh Model Pembelajaran Hybrid Learning Dengan Metode Tutor Sebaya Terhadap Hasil. Febnesia et Al, $7(2), 532-543$.

Mahadewi, N. K. N., Ardana, I. M., \& Mertasari, N. M. S. (2020). Kemampuan Komunikasi Matematis Melalui Model Reciprocal Teaching Berbantuan Media Interaktif. JNPM (Jurnal 
Peningkatan Kemampuan Komunikasi Matematis Siswa Menggunakan Model Pembelajaran Hybrid Learning, Widya Dwi Indriani, Laili Habibah Pasaribu

Nasional Pendidikan Matematika), 4(2), 338. https://doi.org/10.33603/jnpm.v4i2.3606

Nur, S., Surati, \& Rehalat, R. (2017). Jurnal Biology Science \& Education 2017 Irwan. s DKK. Jurnal Biology Science \& Education, 6(2), 138-147.

Nurhanifah, S., Effendi, A., \& Nuraida, I. (2021). Analisis kemampuan komunikasi matematis siswa smp melalui pembelajaran blended learning ditinjau dari tipe kepribadian. S.Nurhanifah, 2(3), $111-118$.

Pasaribu, L. H. (2016). Peningkatan Kemampuan Komunikasi Matematika Siswa Melalui Pembelajaran ( PMR ) Di Kelas VII SMP Negeri 1 Na IX-X AEK Kota Batu. 2(2), 7-12.

Pasaribu, L. H. (2021). Peningkatan Kemampuan Komunikasi dan Kemandirian Siswa melalui Pembelajaran Matematika Realistik Berbantuan Google Classroom Increasing Students , Communication Skills and Independence Through Realistic Mathematics Learning Assisted by Google Classroom. Jurnal Pendidikan Matematika, 11(April), 42-49.

Purnamasari, A., \& Afriansyah, E. A. (2021). Kemampuan Komunikasi Matematis Siswa SMP pada Topik Penyajian Data di Pondok Pesantren. Plus Minus: Jurnal Pendidikan Matematika, 1, 207222.

Putra, I. A. (2015). Orientasi Hybrid Learning melalui Model Hybrid Learning dengan Berbantuan Multimedia di Dalam Kegiatan Pembelajaran. 1(1).

Ramdhani T. (2020). Pengaruh Model Pembelajaran Hybrid Learning Berbantuan Schoology Terhadap Prestasi Belajar Matematika Siswa Kelas XI IPS SMAN 2 Singaraja. Ramadhani T, 11(2), 2599-2600. https://repo.undiksha.ac.id/2221/

Riadi, A., \& Retnawati, H. (2014). Pengembangan Perangkat Pembelajaran untuk Meningkatkan HOTS pada Kompetensi Bangun Ruang Sisi Datar Developing Learning Kit to Improve HOTS for Flat Side of Space Competence. PYTHAGORAS: Jurnal Pendidikan Matematika, 9(2), 126135. http://journal.uny.ac.id/index.php/pythagoras

Rianti Rahmalia, Hajidin, H., \& BI. Ansari. (2020). Peningkatan Kemampuan Komunikasi Matematis Dan Disposisi Matematis Siswa Smp Melalui Model Problem Based Learning. Numeracy, 7(1), 137-149. https://doi.org/10.46244/numeracy.v7i1.1038

Rukajat, A. (2018). Pendekatan penelitian kuantitatif: quantitative research approach. Deepublish.

Wahyuni, S., Yati, M., \& Fadila, A. (2020). Pengembangan Modul Matematika Berbasis REACT terhadap Kemampuan Komunikasi Matematis Peserta Didik. Jambura Journal of Mathematics Education, 1(1), 1-12. https://doi.org/10.34312/jmathedu.v1i1.4542 